Int. J. Electrochem. Sci., 13 (2018) 1985 - 2000

International Journal of

ELECTROCHEMICAL

SCIENCE

www.electrochemsci.org

\title{
Experimental and Theoretical Calculations on Corrosion Inhibition of Bronze in 0.5 M HCl by Some Schiff Bases
}

\author{
Zhe Zhang ${ }^{l}$, Le Ruan ${ }^{1}$, Weipeng Zhang ${ }^{1}$, Yuzeng Lyu ${ }^{2}$, Wei Shang ${ }^{l}$, Yuqing Wen ${ }^{1}$, Xiuying Li ${ }^{l}$, \\ Ling $\mathrm{Wu}^{3}$,Yanni Jiao ${ }^{4}$ \\ ${ }^{1}$ Guangxi Key Laboratory of Electrochemical and Magneto-chemical Functional Materials, College of \\ Chemistry and Bioengineering, Guilin University of Technology, Guilin 541004, PR China \\ ${ }^{2}$ Engineering Research Center of Exploration for hidden Nonferrous and Precious Metal Ore Deposits, \\ Ministry of Education, 541004, PR China \\ ${ }^{3}$ School of Chemistry and Chemical Engineering, Shandong University, Jinan 250100, PR China \\ ${ }^{4}$ Shandong Center for Disease Control and Prevention, Jinan 250014, PR China \\ *E-mail: ruanle@glut.edu.cn
}

doi: $10.20964 / 2018.02 .61$

Received: 10 January 2017 / Accepted: 10 November 2017 / Published: 28 December 2017

The triazol-3-ylamine and three different kinds of Schiff base compounds are self-assembled on bronze surface. Electrochemical impedance spectroscopy and potentiodynamic polarization measurements show that the triazol-3-ylamine and Schiff base self-assembled films can protect bronze from corrosion in $0.5 \mathrm{M} \mathrm{HCl}$ solution. The corrosion efficiency increases with the self-assembly time increasing and reaches a stable value after $8 \mathrm{~h}$. The highest corrosion efficiency of the bronze electrode modified with self-assembled films reaches $95.81 \%$ after immersing in $0.005 \mathrm{M}$ 2,4-Dibromo-6-[(4H-[1,2,4]Triazol3-ylimino)-methyl]-phenol Schiff base solution for $10 \mathrm{~h}$. X-ray photoelectron spectroscopy and scanning electrochemical microscope are used to characterize the inhibitive ability of the selfassembled films. Quantum chemical calculations and dynamic simulations indicate that the triazol-3ylamine and Schiff bases molecules can absorb on the copper surface via chemisorption. The adsorption energy increases with the number of aromatic rings.

Keywords: Schiff base; bronze; inhibition; molecular simulation; XPS.

\section{$\underline{\text { FULL TEXT }}$}

(C) 2018 The Authors. Published by ESG (www.electrochemsci.org). This article is an open access article distributed under the terms and conditions of the Creative Commons Attribution license (http://creativecommons.org/licenses/by/4.0/). 